\title{
Palmitoleic acid (16:1n7) increases oxygen consumption, fatty acid oxidation and ATP content in white adipocytes
}

\author{
Maysa M. Cruz', Andressa B. Lopes ${ }^{4}$, Amanda R. Crisma², Roberta C. C. de Sá', Wilson M. T. Kuwabara², Rui Curi ${ }^{2,3}$, \\ Paula B. M. de Andrade ${ }^{3}$ and Maria I. C. Alonso-Vale ${ }^{1 *}$
}

\begin{abstract}
Background: We have recently demonstrated that palmitoleic acid (16:1n7) increases lipolysis, glucose uptake and glucose utilization for energy production in white adipose cells. In the present study, we tested the hypothesis that palmitoleic acid modulates bioenergetic activity in white adipocytes.
\end{abstract}

Methods: For this, 3 T3-L1 pre-adipocytes were differentiated into mature adipocytes in the presence (or absence) of palmitic (16:0) or palmitoleic (16:1n7) acid at 100 or $200 \mu \mathrm{M}$. The following parameters were evaluated: lipolysis, lipogenesis, fatty acid (FA) oxidation, ATP content, oxygen consumption, mitochondrial mass, citrate synthase activity and protein content of mitochondrial oxidative phosphorylation (OXPHOS) complexes.

Results: Treatment with 16:1n7 during 9 days raised basal and isoproterenol-stimulated lipolysis, FA incorporation into triacylglycerol (TAG), FA oxidation, oxygen consumption, protein expression of subunits representing OXPHOS complex II, III, and V and intracellular ATP content. These effects were not observed in adipocytes treated with 16:0.

Conclusions: Palmitoleic acid, by concerted action on lipolysis, FA esterification, mitochondrial FA oxidation, oxygen consumption and ATP content, does enhance white adipocyte energy expenditure and may act as local hormone.

Keywords: Lipogenesis, Lipolysis, Triglyceride/fatty acid cycle, Bioenergetics, Mitochondria, Beta-oxidation

\section{Background}

White adipose tissue (WAT) stores triacylglycerol (TAG) and its metabolic feature involves lipogenesis and lipolysis, which are associated with changes in the volume of mature adipocytes. The activities of these two metabolic pathways vary with the need to incorporate or release fatty acids (FA), which depends on the nutritional status of the individuals, energy expenditure, hormone levels (e.g. insulin), activities of the enzymes involved in these processes (e.g. ATGL and HSL, FAS and G6PDH) and the heterogeneity existing among white adipose tissue depots [1-3].

Mitochondria play an important role in cellular function, not only as a major site of ATP production, but also by regulating energy expenditure, apoptosis signaling and

\footnotetext{
* Correspondence: alonsovale@gmail.com

${ }^{1}$ Department of Biological Sciences, Institute of Environmental Sciences, Chemical and Pharmaceutical, Federal University of São Paulo, 210, Sao Nicolau St, Diadema 09913-030, Brazil

Full list of author information is available at the end of the article
}

production of reactive oxygen species [4]. The impact of mitochondria function and dysfunction on pre-adipocyte and adipocyte metabolism has attracted a growing body of interest over the last decade [5-7]. There are several reports linking mitochondrial dysfunction with impaired WAT energetic metabolism and the development of obesity, insulin resistance and type 2 diabetes mellitus (T2DM) $[6,8,9]$. Mitochondria are the main site for aerobic glucose and fatty acid oxidation, oxygen consumption, and generation of reactive oxygen species and ATP, which are associated with enhanced basal metabolic rate [10, 11]. Therefore, mitochondria function in WAT might play a key role to control basal metabolic rate and should be considered as a target to be investigated for the development of alternative therapies to treat/prevent obesity and related metabolic disorders.

Among several types of lipids produced and released by adipocytes, palmitoleic acid, a $\omega-7$ monounsaturated fatty acid $(16: 1 \mathrm{n} 7, \mathrm{n} 7)$ synthesized by the desaturation of 
palmitic acid (16:0) by stearoyl-CoA desaturase 1 (SCD1) activity, has been shown to act systemically in peripheral tissues modulating important metabolic processes. Cao and cols [12] showed that palmitoleic acid improves insulin resistance in skeletal muscle and liver and prevents hepatosteatosis. As palmitoleic acid is produced and secreted by WAT, Cao and cols., 2008 [12] named it "lipokine". Palmitoleic acid treatment leads to increased glucose uptake, AKT phosphorylation and raises GLUT1 and GLUT4 protein levels in plasma membrane of skeletal muscle cells [13, 14]. Moreover, palmitoleic acid treatment also enhances AKT, insulin receptor, insulin receptor substrate- 1 and 2 protein phosphorylation in the liver $[12,15]$ and exerts cytoprotective effects in pancreatic $\beta$-cells $[16,17]$.

We investigated herein the effects of palmitoleic acid on WAT bioenergetics. Recently, our group has shown that palmitoleic acid treatment increases adipocyte lipolysis and the content of the major lipases (ATGL and HSL) through a PPAR $\alpha$-dependent mechanism [18]. Besides, this lipokine enhanced glucose uptake and GLUT4 content associated with AMPK activation in these cells, favoring cellular glucose utilization towards energy production [19]. Our hypothesis is that palmitoleic acid increases white adipocyte basal metabolism. To test this proposition, 3 T3-L1 adipocytes were treated with palmitoleic acid $(100 \mu \mathrm{M})$ for 9 days. The results were compared with those obtained with palmitic acid and vehicle under similar experimental protocol. Lipolysis, FA incorporation into lipids and FA conversion into $\mathrm{CO}_{2}$, as well as parameters of mitochondrial bioenergetics (fatty acid oxidation, oxygen consumption and ATP content) and proteic analysis of subunits representing OXPHOS complex (I, II, III, IV e V) were investigated. Treatment with palmitoleic acid did enhance mitochondrial activity as indicated by enhanced ATP generation, proteic expression of II, III, and V complexes of the mitochondrial electron transport chain, FA oxidation and oxygen consumption. Taken together, boosted mitochondrial bioenergetics in combination with raised lipolysis and FA reesterification leads to increased adipocyte energy expenditure via TAG/FA cycle stimulation (futile cycle). Therefore, palmitoleic acid plays a relevant role in WAT metabolism and should be considered as a candidate to be tested in obesity-related therapies.

\section{Methods}

\section{Cell culture}

3 T3-L1 preadipocytes were cultured in Dulbeccos Modified Eagle Medium (DMEM) containing 10\% calf serum and $1 \%$ penicillin-streptomycin until confluence. Differentiation was induced 2 days post-confluence by addition of dexamethasone $(1 \mu \mathrm{M})$, isobutylmethylxanthine $(0.5 \mathrm{mM})$, insulin $(1.67 \mu \mathrm{M})$, and $10 \%$ fetal bovine serum (FBS). After
$48 \mathrm{~h}$, medium was replaced by DMEM containing $10 \%$ FBS and $0.41 \mu \mathrm{M}$ insulin [20]. Cells were cultivated for 9 days in the presence of palmitic acid (16:0), palmitoleic acid (16:1n7), each at $100 \mu \mathrm{M}$ dissolved in ethanol $0.05 \%$ (vehicle), starting from the first day of differentiation (day 0). This dose of palmitoleic acid was found to have no cytotoxic or deleterious effects on cells as evaluated by plasma membrane integrity and DNA fragmentation during differentiation until the day 9 [21]. As we demonstrated before (18) that the palmitoleic acid effects in adipocytes are structure specific, here, we did not add more additional control such as oleic acid $(18: 1 \mathrm{n} 9)$ to the cell cultures. In some experiments, etomoxir (Sigma-Aldrich), an inhibitor of CPT1 activity, was used to inhibit fatty acid oxidation at a concentration of $40 \mu \mathrm{M}$, added $24 \mathrm{~h}$ before the experiments. Cell culture medium was changed every 2 days. All reagents and drugs were purchased from Sigma Chemical Company (St. Louis, MO, USA). Similar procedure was used in our previous studies [18].

\section{Lipolysis measurement}

Lipolysis was estimated as the rate of glycerol (Free Glycerol Determination Kit, Sigma) and free fatty acid (FFA) (NEFA Kit RH series, Wako Diagnostics, CA, USA) released from differentiated 3 T3-L1 cells after 9-day treatment with the fatty acids or vehicle (in some experiments with or without etomoxir) during $30 \mathrm{~min}$ of incubation. Similar procedure was used in our previous studies [18, 22]. Results were expressed as nanomoles of glycerol per $10^{6}$ cells and $\mu \mathrm{Eq} / \mathrm{L}$ of free FA per well for glycerol and FFA, respectively.

\section{Incorporation of $\left[1-{ }^{14} \mathrm{C}\right]$-palmitate into triacylglycerol}

KRH (Krebs Ringer Hepes bicarbonate) buffer, pH 7.4, containing 1\% BSA and $2 \mathrm{mM}$ glucose plus palmitate $(200 \mu \mathrm{M})$, saturated with a gas mixture of $95 \% \mathrm{O}_{2}$ and $5 \% \mathrm{CO}_{2}$, was added to $3 \mathrm{~T} 3-\mathrm{L} 1$ cells after 9-day treatment with FA or vehicle. $\left[1-{ }^{14} \mathrm{C}\right]$-Palmitate was then added to the buffer $(1850 \mathrm{~Bq} /$ tube or well) and left for $2 \mathrm{~h}$ at $37^{\circ} \mathrm{C}$. Cells were then washed three times with phosphate buffered saline (PBS) and Dole's reagent containing isopropanol:n-heptane: $\mathrm{H}_{2} \mathrm{SO}_{4} \quad$ (4:1:0.25 vol/ $\mathrm{vol} / \mathrm{vol}$ ) was added to the remaining reaction mixture for lipid extraction.

The mixture was transferred to polypropylene tubes, which were vortexed three times during the following $30 \mathrm{~min}$. After adding $\mathrm{n}$-heptane $(1.5 \mathrm{~mL})$ and distilled water $(1.5 \mathrm{~mL})$, tubes were vortexed and the mixture was decanted for additional $5 \mathrm{~min}$. The upper phase was collected (in duplicates) and transferred to a scintillation vial for determination of radioactivity trapped into TAG using a $\beta$-counter (1450 LSC, Counter MicroBeta, Trilux; PerkinElmer). Results were expressed as nanomoles of FA 
per $10^{6}$ cells. Similar procedure has been used in our previous studies [18].

\section{Decarboxylation of $\left[1-{ }^{14} \mathrm{C}\right]$-palmitate (fatty acid oxidation)} Differentiated 3 T3-L1 cells (after 9-day treatment with FA or vehicle) were incubated in KRH buffer ( $\mathrm{pH} 7.4)$ containing BSA (1\%) and $\left[1-{ }^{14} \mathrm{C}\right]$-palmitate $(50 \mu \mathrm{M}$, $1850 \mathrm{~Bq} /$ tube or well), saturated with a gas mixture of $95 \% \mathrm{O}_{2}$ and $5 \% \mathrm{CO}_{2}$, for $2 \mathrm{~h}$, at $37{ }^{\circ} \mathrm{C}$. Prior to $2 \mathrm{~h}$ incubation period, each well was covered with a piece of Whatman filter paper and the plate was sealed with parafilm to maintain the atmosphere saturated with the gas mixture. Following the $2 \mathrm{~h}$ incubation, the filter paper was soaked with $0.1 \mathrm{~mL}$ of ethanolamine to trap the $\mathrm{CO} 2$ produced, and $0.2 \mathrm{~mL}$ of $8 \mathrm{~N} \mathrm{H}_{2} \mathrm{SO}_{4}$ was injected into the wells with the aid of a needle to rupture the cells. After $45 \mathrm{~min}$ of $\mathrm{CO}_{2}$ trapping, the filter paper was removed and transferred to scintillation vials for radioactivity counting [23, 24]. Results were expressed as nanomoles of oxidized $\left[1-{ }^{14} \mathrm{C}\right]$-palmitate per $10^{6}$ cells.

\section{Oxygen consumption}

Oxygen consumption rates in intact cells were measured as an indication of mitochondrial respiratory activity. After 9-day treatment with palmitic acid $(100 \mu \mathrm{M})$, palmitoleic acid $(100 \mu \mathrm{M})$ or vehicle, 3 T3-L1 cells were gently tripsinised, re-suspended in $\mathrm{KRH}(\mathrm{pH}$ 7.4) containing BSA (0.1\%), and transferred to the oxygraph (OROBOROS Oxygraph-2 k). The oxygraph chambers were previously equilibrated with KRH containing BSA $0.1 \%$ at $37^{\circ} \mathrm{C}$. Carbonyl cyanide m-chlorophenyl hydrazine (CCCP, $1 \mu \mathrm{M}$ f.c.) was added as positive control for maximal respiratory rate (uncoupling) determination. Oxygen consumption rates were normalized by cell number and expressed as \% of the control [25]. Oxygen consumption was also measured in mature 3 T3-L1 adipocytes (9 days after differentiation) treated for $24 \mathrm{~h}$ with palmitoleic acid $(200 \mu \mathrm{M})$ or vehicle.

\section{ATP content determination}

ATP content was determined in 3 T3-L1 cell lysates after 9 days of treatment with FA or vehicle (in the presence or absence of etomoxir) using an ATP bioluminescence assay kit (Roche, Mannheim, Germany). Measurements were performed in a luminometer (Biotech, model: Synergy HT). Results were normalized by cell number and expressed as percentage of control [26].

\section{Western blot analysis}

After treatment with FA or vehicle for 9 days, 3 T3-L1 cells were homogenized and processed in buffer composed in mM by: 50 HEPES, $40 \mathrm{NaCl}, 50 \mathrm{NaF}, 2$ EDTA, 10 sodium pyrophosphate, 10 sodium glycerophosphate, 2 sodium orthovanadate, and 1\% Triton-X100 and EDTA-free protease inhibitors. Identical amounts of protein aliquots from 3 T3-L1 cell lysates were resolved on Nupage gradient gels (4-12\%, Invitrogen Life Technologies) and transferred to nitrocellulose membranes. After blockage with $5 \%$ milk for $1 \mathrm{~h}$, membranes were overnight incubated at $4{ }^{\circ} \mathrm{C}$ with the following primary antibodies: mitochondrial complex I subunit NDUFB8 (20 kDa), complex II subunit $30 \mathrm{kDA}(30 \mathrm{kDa})$, complex III subunit Core $2(48 \mathrm{kDa})$, COXIV subunit I $(40 \mathrm{kDa})$, complex V ATP synthase subunit alpha (53 kDa) (OXPHOS kit, MitoSciences, Inc.) and gamma-tubulin $(\sim 50 \mathrm{kDa} \# 5886$, Cell Signaling, Beverly, MA, USA) in 5\% milk (1:1000). After washing, membranes were subsequently incubated with appropriate peroxidase-conjugated secondary antibody (1:5000) for $1 \mathrm{~h}$ and developed using the ECL enhanced chemiluminescence substrate (GE Healthcare Life Sciences, Björkgatan, Uppsala). Densitometric analyses were performed using the ImageJ software (National Institutes of Health, Bethesda, MD).

\section{RNA extraction, reverse transcription and quantitative real-time PCR (real-time qRT-PCR)}

Total RNA from 3 T3-L1 cell lysates was extracted using Trizol (Invitrogen Life Technologies), analyzed for quality on agarose gel and absorbance ratios of $260 / 280 \mathrm{~nm}$ and 260/230 nm, and reverse transcribed to cDNA using the SuperScript III cDNA kit (Invitrogen Life Technologies). Gene expression was evaluated by real-time qRT-PCR using a Rotor Gene (Qiagen, Roermond, Netherlands) and SYBR Green as fluorescent dye (Qiagen) with 36B4/Rplp0 as housekeeping gene. The reaction conditions were as follows: $95{ }^{\circ} \mathrm{C}$ for $5 \mathrm{~min}$, then 40 cycles of $95{ }^{\circ} \mathrm{C}$ for $5 \mathrm{~s}$ and $60{ }^{\circ} \mathrm{C}$ for $10 \mathrm{~s}$. PCR products were run on agarose gel to confirm the size of the fragment and specificity of amplification. Primers used were: Pnpla2 (5'-3' sense: GGTCCTCTGCATCCCTCCTT; 5'-3'antisense: CTGTC CTGAGGGAGATGTC), $a P 2\left(5^{\prime}-3^{\prime}\right.$ 'sense: AAGGTGAA G AGCATCATAACCCT; 5'-3'antisense: TCACGCCTTT CATAACACATTCC) and 36B4 (5' -3' $^{\prime}$ sense: TAAAGA CTGGAGACAAGGTG; 5'-3'antisense: GTGTACTCAG TCTCCAC AGA). Data were obtained as ct values (ct= cycle number at which logarithmic PCR plots cross a calculated threshold line) and used to determine $\Delta \mathrm{ct}$ values $(\Delta \mathrm{ct}=$ (ct of the target gene) - (ct of the housekeeping gene). Data were expressed as arbitrary units using the following calculation: [expression $=1000 \times\left(2^{-\Delta c t}\right)$ arbitrary units (AU)].

\section{Mitochondrial mass determination}

The methodology was based on the protocol used by Shen et al. [25]. A fluorescent probe (Mito-Tracker Green FM; Molecular Probes, Eugene, OR, USA) was used to determine the mitochondrial mass of adipocytes [27]. Mature adipocytes (9 days of differentiation) were 
treated with palmitic or palmitoleic acid, trypsinised and centrifuged at $1500 \times \mathrm{g}, 4{ }^{\circ} \mathrm{C}$, for $5 \mathrm{~min}$, resuspended in $\mathrm{KRH}$ buffer containing $0.1 \%$ BSA $(w / v)$ and then incubated with $0.1 \mu \mathrm{mol} / \mathrm{L}$ MitoTracker Green FM in KRH buffer for $30 \mathrm{~min}$ at $37{ }^{\circ} \mathrm{C}$. Cells were centrifuged at $1500 \times \mathrm{g}, 4{ }^{\circ} \mathrm{C}$, for $5 \mathrm{~min}$ and resuspended in $400 \mu \mathrm{L}$ of fresh KRH buffer. Fluorescence measurements were carried out in CALIBUR cytometer (BD) in the FL1 channel. Ten thousand events were analyzed per experiment. Data were analyzed using Cell Quest software.

\section{Citrate synthase activity assay}

Citrate synthase (EC 4.1.3.7) maximum activity was determined as previously described by Alp et al. [28]. Briefly, after 9 days treatment with FA or vehicle, 3 T3L1 cells were homogenized (vortex) in extraction buffer containing Tris- $\mathrm{HCl}(50 \mathrm{mM})$, EDTA $(1 \mathrm{mM})$, leupeptin $(50 \mu \mathrm{M})$, and aprotinin $(5 \mu \mathrm{M}), \mathrm{pH} 7.4$, and centrifuged $\left(16,000 \mathrm{~g}, 30 \mathrm{~s}, 4{ }^{\circ} \mathrm{C}\right)$. The assay buffer consisted of Tris $\mathrm{HCl}(100 \mathrm{mM})$, DTNB $(0.2 \mathrm{mM})$, acetyl-CoA (100 mM), and Triton (1\%), $\mathrm{pH}$ 6.5. The reaction was started by adding $10 \mathrm{uL}$ of oxaloacetic acid $(500 \mathrm{mM})$ $25{ }^{\circ} \mathrm{C}$. The absorbance was monitored for $10 \mathrm{~min}$ at $420 \mathrm{~nm}$. Protein concentration in the supernatants was determined using a $\mathrm{BCA}^{\circ}$ protein assay kit (PIERCE Biotechnology, Rockford, IL). The maximal enzyme activity was expressed as micromoles per minute per microgram of protein.

\section{Statistical analysis}

Results are expressed as mean \pm SEM. One-Way ANOVA followed by Tukey post-hoc test were used to compare the effects of different treatments. Analysis was performed using GraphPad Prism 5.0 software (GraphPad Software, Inc., San Diego, CA, USA). The level of significance was set at $p \leq 0.05$.

\section{Results}

First, we examined the effect of 9-day treatment with palmitoleic or palmitic acid on 3 T3-L1 adipocyte lipolysis. Palmitoleic acid increased both basal (by 3 -fold) and stimulated (by 3.5-fold) lipolysis as measured by the glycerol released to the medium [mean \pm SEM, Basal (vehicle: $828.9 \pm 95.4 ; 16: 1 n 7: 3027.2 \pm 511)$ and stimulated (vehicle: $1760.3 \pm 174 ; 16: 1 \mathrm{n} 7: 6077.7 \pm 822$ ) nMol/10 cells, $p<0.05$ ] (Fig. $1 \mathrm{a}$ and b, respectively). Pnpla2 mRNA levels were significantly increased (by 30\%) in cells treated with palmitoleic acid (Fig. 1c). We further investigated whether 16:1n7 would also promote an increase in free fatty acid (FFA) release by these cells (dictated by a glycerol/FA proportion of 1:3, as products of TAG hydrolysis). Palmitoleic acid did not cause significant increase of FFA release into the medium, that is, no difference was observed among the groups. Interestingly, this profile was slightly altered by pretreatment with etomoxir (a potent inhibitor of fatty acid mitochondrial uptake and oxidation), since $16: 1 \mathrm{n} 7$ + etomoxir treated cells presented an increase by $5 \%$ in the FFA release into the medium (mean \pm SEM, 16:1n7: $59.2 \pm 0.8 ; 16: 1 \mathrm{n} 7$ + etomoxir: $63.3 \pm 0.44 \mu \mathrm{Mol} / \mathrm{L}, p<0.05$ ) (Fig. 3b). We did not observe any effect of palmitic acid on lipolytic activity.

We hypothesized that palmitoleic acid should boost TAG lipolysis/FA re-esterification cycle. To test this hypothesis, we analyzed if FA esterification was raised in cells treated with palmitoleic acid. Indeed, an increase of $\left[1-{ }^{14} \mathrm{C}\right]$-palmitate incorporation into TAG (by $40 \%$ ) was observed in cells treated with palmitoleic acid (mean \pm SEM, vehicle: $23.42 \pm 0.5 ; 16: 1 \mathrm{n} 7$ : $28.73 \pm 0.8 \mathrm{nMol} / 10^{6}$ cells, $p<0.05$ ) (Fig. 2a). Moreover, aP2 mRNA levels were positively regulated by palmitoleic acid (Fig. 2b). These results show that FA incorporation into TAG is increased in 3 T3-L1 adipocytes treated with palmitoleic acid. No effect on the synthesis of TAG was observed in cells treated with palmitic acid.

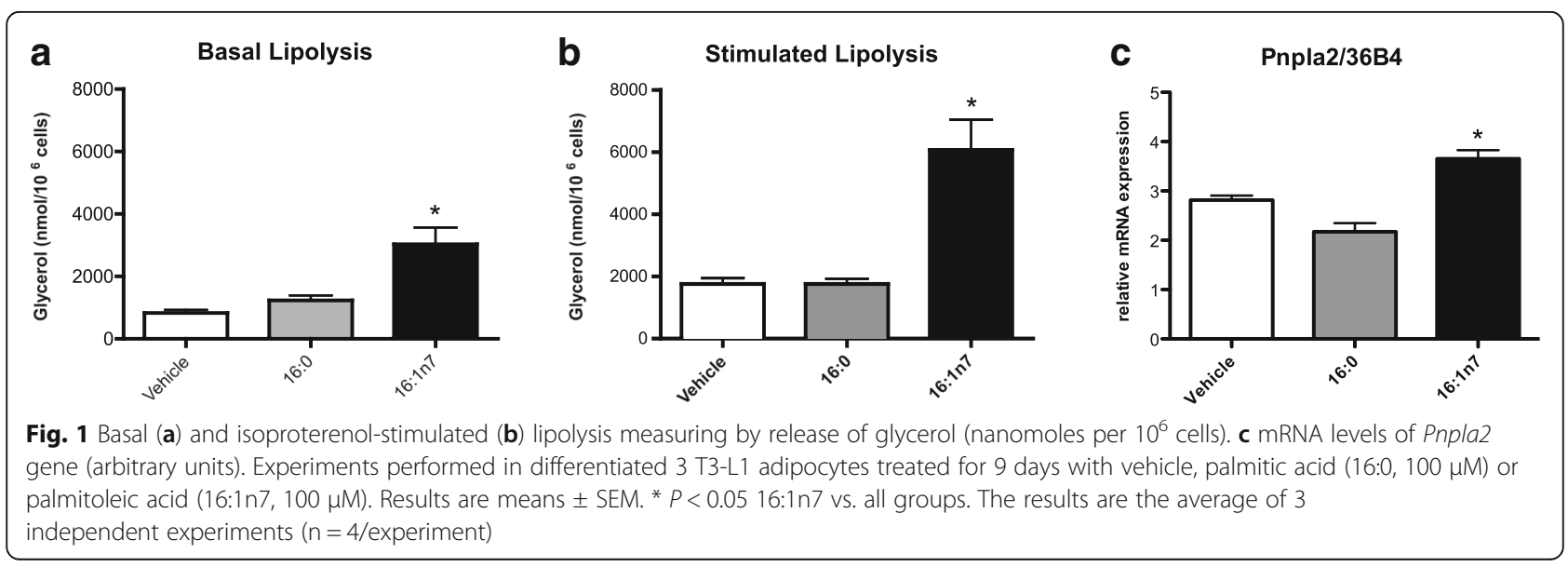



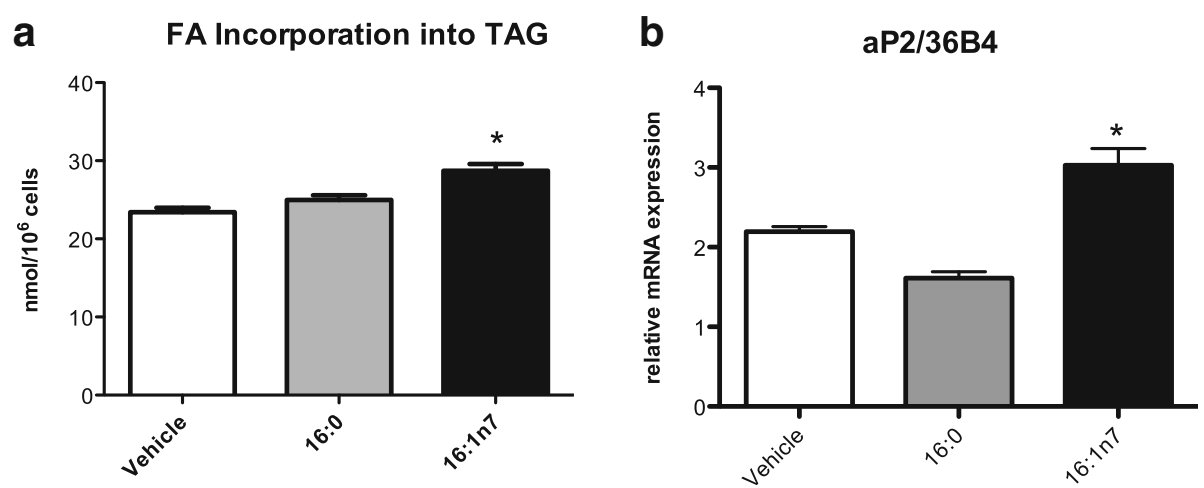

Fig. 2 a $\left[1-{ }^{14} \mathrm{C}\right]$-palmitate incorporation into TAG (nanomoles of incorporated $\left[1-{ }^{14} \mathrm{C}\right]$-palmitate per $10^{6} \mathrm{cells}$ ) and $\mathbf{b}$ mRNA levels of aP2 (arbitrary units). Experiments performed in differentiated 3 T3-L1 adipocytes treated for 9 days with vehicle, palmitic acid (16:0, 100 $\mu \mathrm{M})$ or palmitoleic acid $(16: 1 \mathrm{n} 7,100 \mu \mathrm{M})$. Results are means \pm SEM. ${ }^{*} P<0.0516: 1 \mathrm{n} 7 \mathrm{vs}$. all groups. The results are the average of 3 independent experiments $(n=6$ /experiment)

Next, we investigated if palmitoleic acid could enhance FA beta-oxidation. The conversion of $\left[{ }^{14} \mathrm{C}\right]-$ palmitate to $\mathrm{CO}_{2}$ was raised by $30 \%$ in cells treated with palmitoleic acid when compared to control cells (mean \pm SEM, vehicle: $0.8 \pm 0.033 ; 16: 1 \mathrm{n} 7: 1.03 \pm 0.05$ $\mathrm{nMol} / 10^{6}$ cells, $p<0.05$ ) (Fig. 3a). No change in FAO was observed in cells treated with palmitic acid when compared to control. Disruption of fatty acid oxidation by etomoxir in a dose of $40 \mu \mathrm{M}$ was confirmed in this experiment by partial attenuation $(\sim 25 \%)$ of fatty acid oxidation.

Other mitochondrial parameters, such as ATP levels and oxygen consumption, were also measured in $3 \mathrm{~T} 3-\mathrm{L} 1$ cells. FA oxidation is a metabolic pathway that requires oxygen to take place. We performed oxygen consumption measurements in 3 T3-L1 adipocytes treated with fatty acids using a modular system for high-resolution respirometry (HRR), the Oroboros Oxygrapk-2 k (O2k).
Oxygen consumption was raised in cells treated with palmitoleic acid for 9 days (by 13\%, Fig. 4a) and $24 \mathrm{~h}$ (by $10 \%$, Fig. 4b). So, palmitoleic acid stimulates basal energetic metabolism in white adipocytes. Palmitic acid treatment did not affect oxygen consumption in any of the conditions studied.

We further investigated the palmitoleic effects on ATP content. 16:1n7, but not 16:0 treatment of the cells, raised ATP levels by $17 \%$ (mean \pm SEM, vehicle: $100 \pm 1.72$; 16:1n7: $119.8 \pm 1.51$ percentage of control, $p<0.05$ ) (Fig. 5). We hypothesized that raised FAO, secondary to raised lipolysis promoted by $16: 1 \mathrm{n} 7$, elevates ATP production (corroborating oxygen consumption) in a magnitude capable of overcome its consumption (raised by the exacerbation of TAG/FA cycle). This hypothesis is supported here, by the experiments performed under pretreatment of the cells with etomoxir, that completely prevented the increment on ATP content induced by palmitoleic acid (Fig. 5).
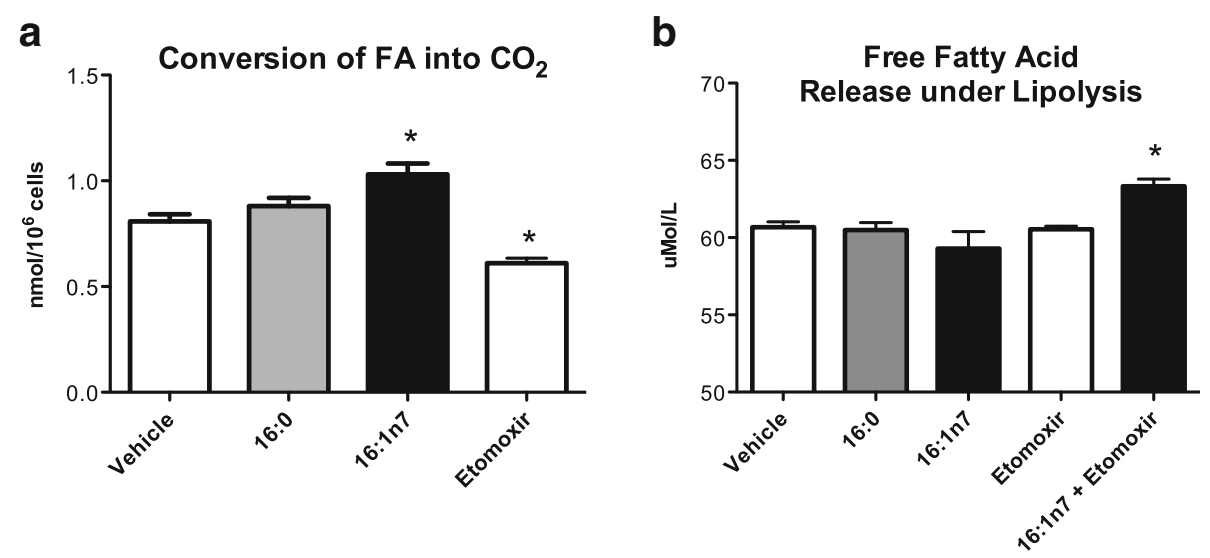

Fig. 3 a Conversion of $\left[1-{ }^{14} \mathrm{C}\right]$-palmitate into $\mathrm{CO}_{2}$ (nanomoles of converted $\left[1-{ }^{14} \mathrm{C}\right]$-palmitate into $\mathrm{CO}_{2}$ per $10^{6}$ cells) and $\mathbf{b}$ Free fatty acids released under lipolysis ( $\mu \mathrm{Mol}$ per liter per well). Experiments performed in 3 T3-L1 adipocytes under 9-days treatment with vehicle, etomoxir $(40 \mu \mathrm{M})$, palmitic acid $(16: 0,100 \mu \mathrm{M})$ or palmitoleic acid $(16: 1 \mathrm{n7}, 100 \mu \mathrm{M})$. Results are means \pm SEM. ${ }^{*} P<0.05$ vs. all groups. The results are the average of 3 independent experiments ( $n=4$ /experiment) 

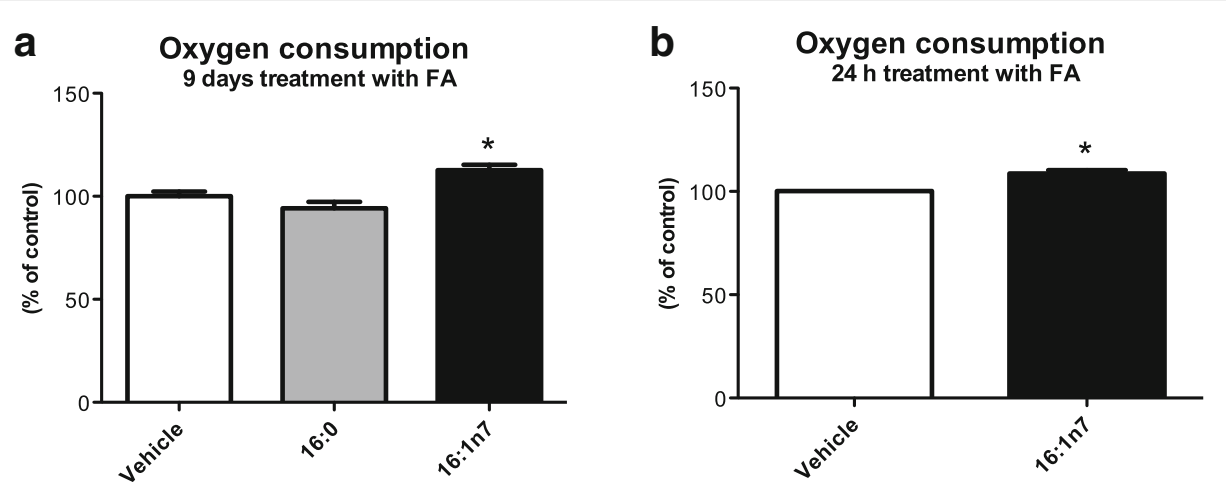

Fig. 4 Oxygen consumption by 3 T3-L1 adipocytes under (a) chronic ( 9 days) and $\mathbf{b}$ acute ( $24 \mathrm{~h}$ ) treatments with vehicle, palmitic acid (16:0, $100 \mu \mathrm{M}$, respectively) or palmitoleic acid (16:1n7, 200 or $100 \mu \mathrm{M}$, respectively). Results expressed as percentage of control. Results are presented as means \pm SEM. ${ }^{*} P<0.0516: 1 n 7$ vs. all groups. The results are the average of 3 independent experiments $(n=6 /$ experiment)

Since the augmented ATP concentration observed in our studies suggest an increment in mitochondrial OXPHOS efficiency, we next evaluated protein expression of subunits representing complex II, III, and V of the mitochondrial electron transport chain. Complex II and III were positively modulated by palmitoleic acid (by $54 \%$ and by $36 \%$, respectively), but not by palmitic acid, when compared with the control group (Fig. 6b and c). Likewise, complex $\mathrm{V}$ was positively modulated by palmitoleic acid (by 40\%) when compared to the control group (Fig. 7e). However, palmitoleic acid did not elicit any change in the content of mitochondrial complexes I and IV (Fig. 6a and d, respectively).

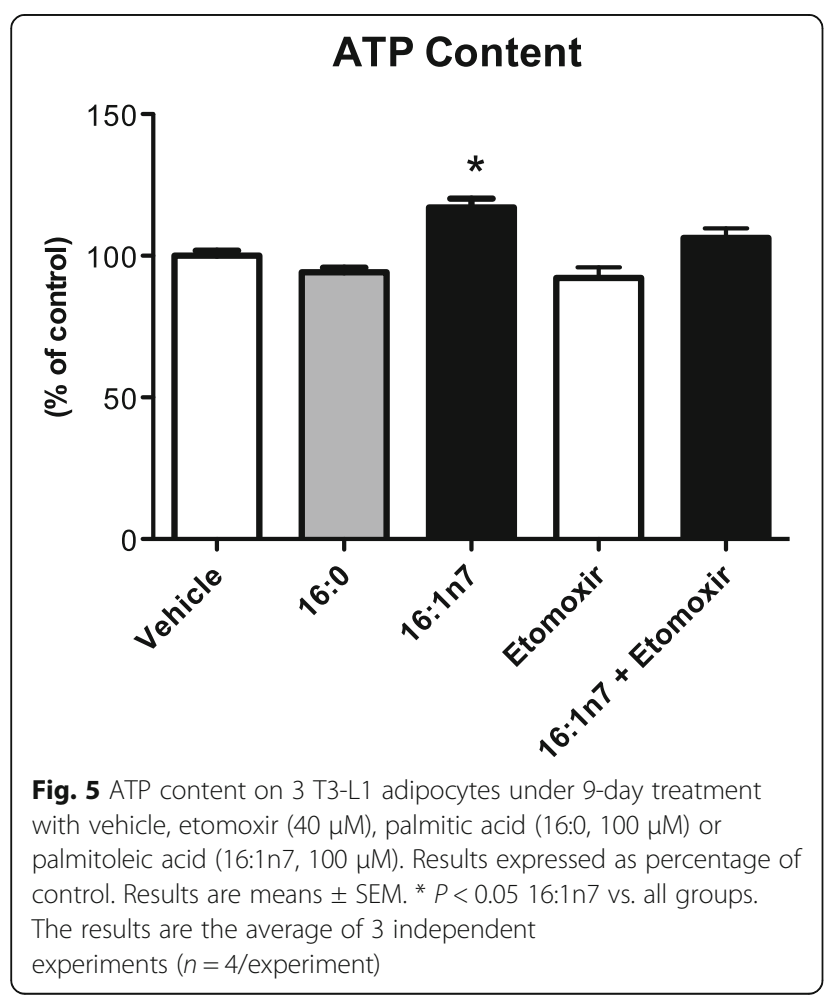

Mitochondria mass was evaluated by flow cytometry, according to the methodology proposed by Shen and colleagues [25]. A decrease of $\sim 10 \%$ in mitochondria mass was observed in cells treated with palmitoleic acid. There was no effect of palmitic acid on this parameter (Fig. 7a). Another parameter to measure mitochondria content is citrate synthase activity. Palmitoleic acid (but not palmitic acid) led also to a reduction of $\sim 10 \%$ in citrate synthase activity (mean \pm SEM, vehicle: $0.031 \pm 0.0005 ; 16: 1 \mathrm{n} 7$ : $0.024 \pm 0.0008 \mu \mathrm{Mol} / \mathrm{min} / \mu \mathrm{g}$ of protein, $p<0.05$ ) (Fig. 7b), when compared with the control group.

\section{Discussion}

3 T3-L1 adipocytes were treated with palmitic acid or palmitoleic acid, being the latter recently described to induce important effects on carbohydrate and lipid metabolism in liver and skeletal muscle $[12,15,29,30]$. We have previously demonstrated that palmitoleic acid controls important metabolic processes also in adipose tissue. We reported increased lipolysis and glucose uptake, together with changes in expression of related genes and proteins (ATGL, HSL, AMPK and GLUT4) in white adipocytes $[18,19]$. In the present work, we observed that palmitoleic acid modulates other aspects of adipocyte metabolism, mainly mitochondria bioenergetics. Palmitoleic acid (but not palmitic acid) enhanced energy expenditure in adipocytes through TAG/FA cycle stimulation, FA oxidation, oxygen consumption and increased protein expression of subunits representing complex II, III, and V of the mitochondrial electron transport chain. The treatment of the adipocytes with palmitic acid (16:0), different from palmitoleic (16:1n7), showed no marked effect on the parameters herein studied.

An increase in both basal and isoproterenol-stimulated lipolysis, together with augmented gene expression of the Pnpla2, were observed in 3 T3-L1 cells treated with palmitoleic acid ( 9 days, from the induction of preadipocyte differentiation) when compared to the palmitic acid 


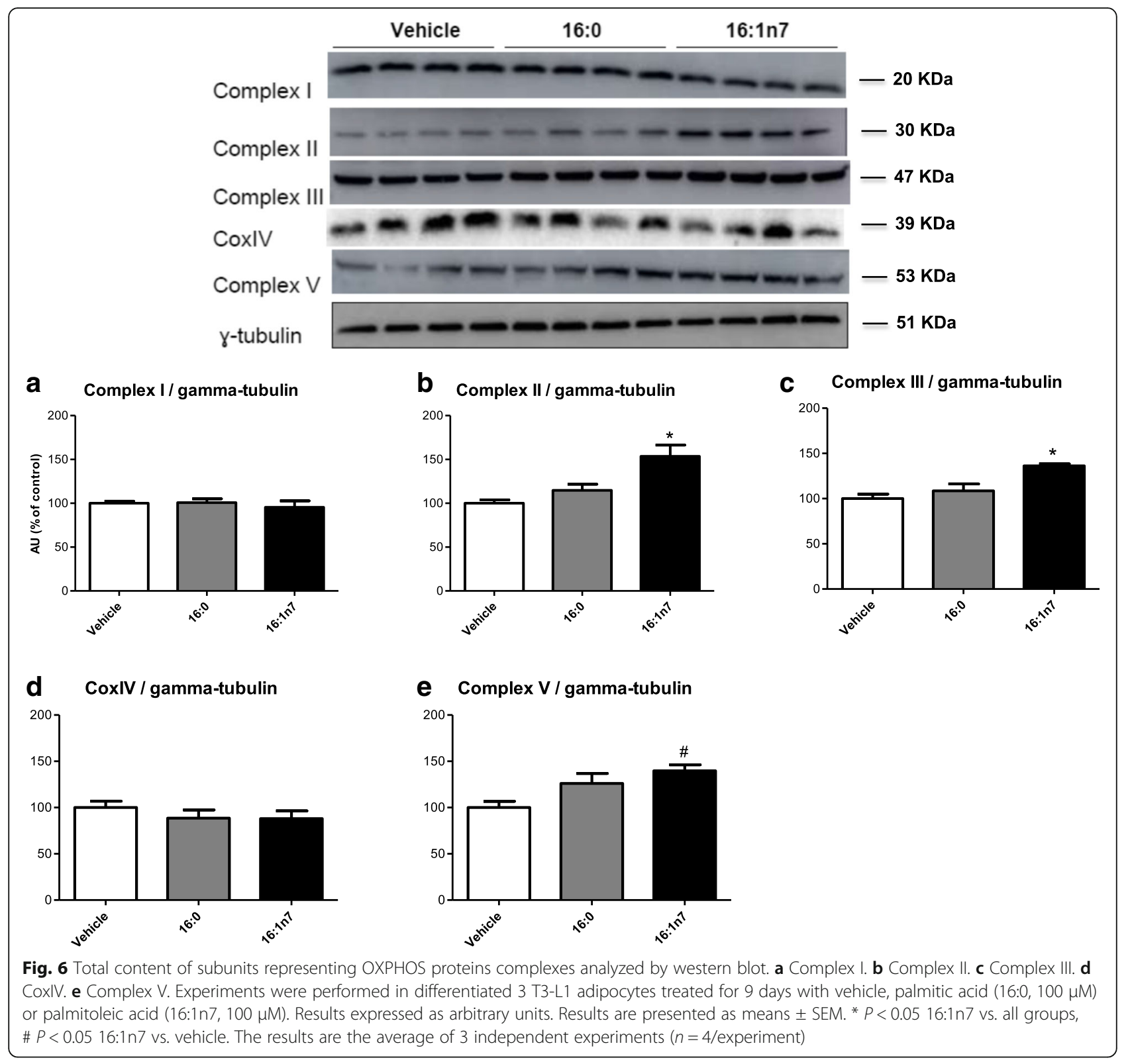

and control groups. These findings corroborate previous ex vivo results obtained by our group [18]. We have shown that there is an increase of lipolysis in primary adipocytes extracted from epididymal fat pads of mice treated with palmitoleic acid (by gavage) for 10 days and also, in mature (6 days post-differentiation) 3 T3-L1 cells treated with palmitoleic acid (by $24 \mathrm{~h}$ ), via a PPAR $\alpha$ dependent mechanism. The increment in lipolysis promoted by palmitoleic acid was estimated according to the concentration of glycerol released into the medium. A concomitant increment of FFA released from adipocytes [dictated by a glycerol/FA proportion of 1:3, as products of TAG hydrolysis] treated with palmitoleic acid was not observed. This suggests that the fatty acids originated from lipolysis of cells treated with palmitoleic acid could be used in other metabolic pathways such as: (1) re-esterification, (2) mitochondrial oxidation or (3) mitochondrial uncoupling, including the possibility of overlapping pathways. We ruled out mitochondrial uncoupling due to the fact that cellular ATP levels were augmented upon palmitoleic acid treatment (Fig. 5) and UCP1/2 mRNA levels are not altered under this condition (data not shown).

To test the hypothesis 1, we analyzed if FA esterification was increased in cells treated with palmitoleic acid for 9 days. Palmitoleic acid did increase $\left[1-{ }^{14} \mathrm{C}\right]$-palmitate incorporation into TAG as well as aP2 mRNA levels in adipocytes. $a P 2$ gene encodes a protein involved in 

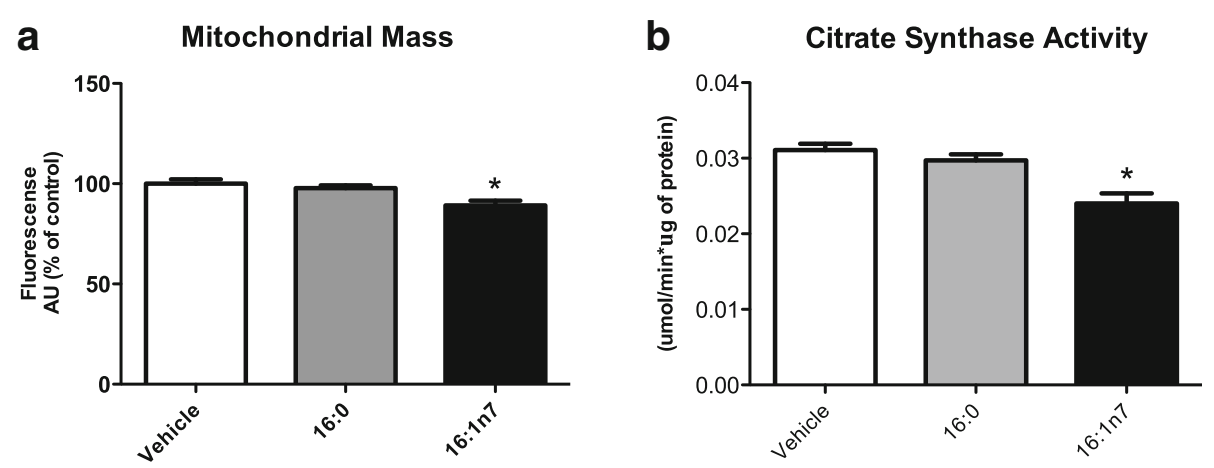

Fig. 7 a Mitochondrial mass (percentage of florescence). b Citrate synthase activity (micromoles per minute per microgram of protein). Experiments performed in differentiated 3 T3-L1 adipocytes treated for 9 days with vehicle, palmitic acid (16:0, 100 $\mu \mathrm{M})$ or palmitoleic acid $(16: 1 \mathrm{n7}, 100 \mu \mathrm{M})$. Results are means \pm SEM. ${ }^{*} P<0.0516: 1 \mathrm{n} 7 \mathrm{vs}$. all groups. The results are the average of 3-4 independent experiments ( $n=6$ /experiment)

FA uptake and transport to be then associated to coenzyme A (a reaction catalyzed by acyl-CoA synthetase) to generate acyl-CoA. Corroborating these findings, we demonstrated an increase in the generation of glycerol 3-phosphate (G3-P) via glycolysis (required for esterification of fatty acids to TAG), as evidenced by the higher rates of glucose incorporation into the glycerol fraction of TAG [18]. In another recent work published by our group [19] an increase of glucose uptake by adipocytes, via a mechanism that involves AMPK, promoted by palmitoleic acid was demonstrated. This observation is compatible with increased G3-P formation from glucose, since there was not seen any increase in gene expression of the glyconeogenic regulatory enzyme PEPCK or in glycerol kinase activity in this study, the two other possible sources of G3-P [31]. These results suggest that palmitoleic acid promotes FA re-esterification and TAG/FA futile cycle stimulation.

A concomitant increase in lipolysis and FA reesterification implies in stimulation of the substrate cycle (or "futile" cycle) TAG/FA cycle [32, 33]. In mammals, an increase in this cycle activity together with raised fatty acid oxidation can lead to augmented basal metabolic rate (BMR) and total energy expenditure [34] as well as greater sensitivity to hormonal control of energy metabolism (e.g. lipolytic and lipogenic activities). Additionally, the stimulation of this cycle is a mechanism associated with induction of thermogenesis during cold exposure [35] and also when plasma leptin levels are high [32].

In the next step, we investigated if palmitoleic acid could enhance FA beta-oxidation and oxygen consumption. Maassen, Romijn and Heine [36] suggested that FA oxidation in adipocytes might also contribute to the retention of FA in these cells, thus avoiding excessive release of FA into the circulation when lipolysis is stimulated reducing lipotoxicity. We observed an increase (by 30\%) in FA oxidation in 3 T3-L1 adipocytes treated with palmitoleic acid. This effect maybe underestimated due to the fact that palmitoleic acid can compete with labeled $\left[1-{ }^{14} \mathrm{C}\right]$-palmitate (50uM) added to the medium during this test for the beta-oxidation pathway.

Despite the fact that some studies describe FA oxidation as a minor metabolic pathway in white adipocytes, especially when compared to FA re-esterification [37-39], Dib, Bugge and Collins [40] claim that FA oxidation in WAT is not negligible and contributes from 5 to $10 \%$ of the BMR in lean and obese adults, respectively. Noteworthy, the percentage of endogenous FA oxidized in primary rat white adipocyte was calculated and found to be around $0.2 \%$, what seems small when compared to re-esterified $(\sim 50 \%)$ and released endogenous FFA $(\sim 50,1 \%)$ [41]. We estimated herein the amount of FFA released by the cells, which were around 40 nmoles $/ 10^{6}$ cells. The estimated FFA released is much lower than the amount of glycerol released (by 70 -fold) but it is much higher than the amount of $\mathrm{CO}_{2}$ generated $\left(\sim 1 \mathrm{nmol} / 10^{6}\right.$ cells). This finding corroborates the data that FFA reesterification and endogenously released FFA are the major pathways when compared to FFA oxidation. Anyway, pretreatment with etomoxir, that has been shown to bind CPT-1 with high affinity, thereby preventing mitochondrial uptake of fatty acids [42], caused an increment in the FFA release into the medium by the cells treated with palmitoleic acid. The disruption of fatty acid oxidation by etomoxir was confirmed here, by the attenuation of fatty acid oxidation.

Wang and cols [41] claim that FFA oxidation assays are usually performed during a short period of time (a 2-h period or so) and, if extrapolated to years, this oxidative pathway could reduce more than $1 \mathrm{~kg}$ of fat mass per $50 \mathrm{~kg}$ of fat mass per year in humans depending on if there is combined fasting or not. Therefore, WAT FAO 
might be not so negligible as previously thought to be. Actually, efficient mitochondrial WAT FAO may increase respiratory capacity, reduce adipocyte size, enhance lipolysis and reduce lipotoxicity [6, 38, 43]. A recent study with human twins showed that adiposity is correlated with downshifting of FAO and that, indeed, mitochondrial biogenesis, oxidative metabolic pathways and OXPHOS proteins in subcutaneous adipose tissue are downregulated in acquired obesity [44]. Altogether these studies corroborate the hypothesis that mitochondrial WAT FAO stimulation has relevant effects on body energy balance.

Together with increased FAO, an increment in basal $\mathrm{O}_{2}$ consumption was observed in $3 \mathrm{~T} 3-\mathrm{L} 1$ cells treated with palmitoleic acid, which suggests an increase in BMR of these cells. This enhancement in oxygen consumption could be explained by an increase in FAO, mitochondrial uncoupling or both [45].

The augmentation in $\mathrm{O}_{2}$ consumption observed in the present study supports the consistent raise in FAO catabolic pathway. In addition, cellular ATP levels were raised by $17 \%$ as well as protein levels of the subunit ATP-5A of the OXPHOS complex V (ATP synthase, Fig. 6e) upon palmitoleic acid treatment. Pretreatment with etomoxir completely prevented this effect, demonstrating the dependent effect of FAO increase for the palmitoleic effects here observed. Altogether, the raise in all these mitochondrial parameters: oxygen consumption, FAO and ATP generation, points out to enhanced mitochondrial oxidative phosphorylation efficiency [46] upon palmitoleic acid treatment. Although the palmitoleic acid effects seems mild, according Gao and colleagues [47] mitochondria do not require major changes to reflect a prominent metabolic effect. In contrast, abrupt mitochondrial changes are toxic and induce cell death. This work showed that both sudden increases or decreases cause mitochondrial damage by high levels of glucose and free fatty acids in 3 T3-L1 adipocytes.

At first, palmitoleic acid-induced increase in cellular ATP levels seems odd since raised AMP/ATP ratio is the main factor that leads to AMPK phosphorylation and activation. In addition, given the crucial role of the acyl-CoA synthetase in the re-esterification of FA released from lipolysis [48], this finding looks indeed unexpected. Acyl-CoA synthetase catalyzes the activation of $1 \mathrm{FA}$ in 1 acyl-CoA, consuming 1 ATP (1 AMP and pyrophosphate). In fact, it utilizes two equivalents of ATP since pyrophosphate is cleaved into 2 inorganic phosphate molecules, breaking a high-energy phosphate bond. Nevertheless, FAO generates NADH and $\mathrm{FADH}_{2}$, which enter the electron transport chain to produce ATP. Our hypothesis is that raised FAO (secondary to raised lipolysis) promoted by $16: 1 \mathrm{n} 7$, elevates ATP production (corroborating oxygen consumption increase) in a magnitude capable of overcome its consumption (raised by the exacerbation of TAG/FA cycle). This hypothesis is supported here, by the experiments performed under pretreatment of the cells with etomoxir, that completely prevented the increment on ATP content induced by palmitoleic acid. Actually, Baldwin et al. [49] calculated that the energy required for TAG/FA cycle is around 8 molecules of ATP per release and re-esterification of 3 molecules of FA (2,7 ATP/FA). This energetic demand could be provided by mitochondria FAO (fasting) and glucose oxidation (fed state) [50]. Indeed, the effectiveness of fuel oxidation by mitochondrial relies on mitochondria content, mitochondrial activity and mitochondrial efficiency to synthesize ATP from the oxidation of substrates [46]. Noteworthy, relative to their dry mass, FA provide twice as much ATP as carbohydrates: six times more when comparing stored FA to stored glycogen [51]. It is importante to emphasize that cell lines in culture, including 3 T3-L1 cells, display a high rate of glycolysis. However, we can assume herein that glycolysis is not responsible for the increament in ATP levels, since the results showed that when CPT1 was inhibited in cells treated with palmitoleic acid, the ATP levels increase was completely abolished.

The augmented ATP concentration observed corroborates our data of an increment in mitochondrial OXPHOS efficiency (increased protein expression of subunits representing OXPHOS complex II, III and IV) in cells treated with 16:1n7. Raised ATP consumption is observed when lipolysis occurs simultaneously with FA re-esterification (TAG/FA cycle) [52]. As a paradox, augmented basal and isoproterenol stimulated lipolysis (promoted by 16:1n7) increases AMP/ATP ratio, which is known to promote AMPK activation [53], that, in turn, would stimulate catabolic pathways in order to increase ATP production, corroborating the data of raised beta-oxidation and oxygen consumption demonstrated herein. These findings also support the previous data shown by our group that $16: 1 \mathrm{n} 7$ led to an increase on glucose uptake and oxidation associated with AMPK activation [19].

WAT mitochondria are potential targets in the search for the development of therapies to prevent and treat obesity, inflammation, insulin resistance and related disorders $[6,40,54]$. Ahmadian et al. (56) suggested that augmented lipolysis could result in a change in adipocyte metabolism via greater use of FA and enhanced energy expenditure, protecting against obesity [55]. The fact that palmitoleic acid reduced citrate synthase activity corroborates the results of decreased mitochondrial mass under the effect of this fatty acid, suggesting more efficient mitochondria, although fewer in number, in these adipocytes treated with palmitoleic acid. Indeed, relevant metabolic parameters of these cells were increased, such as oxygen 


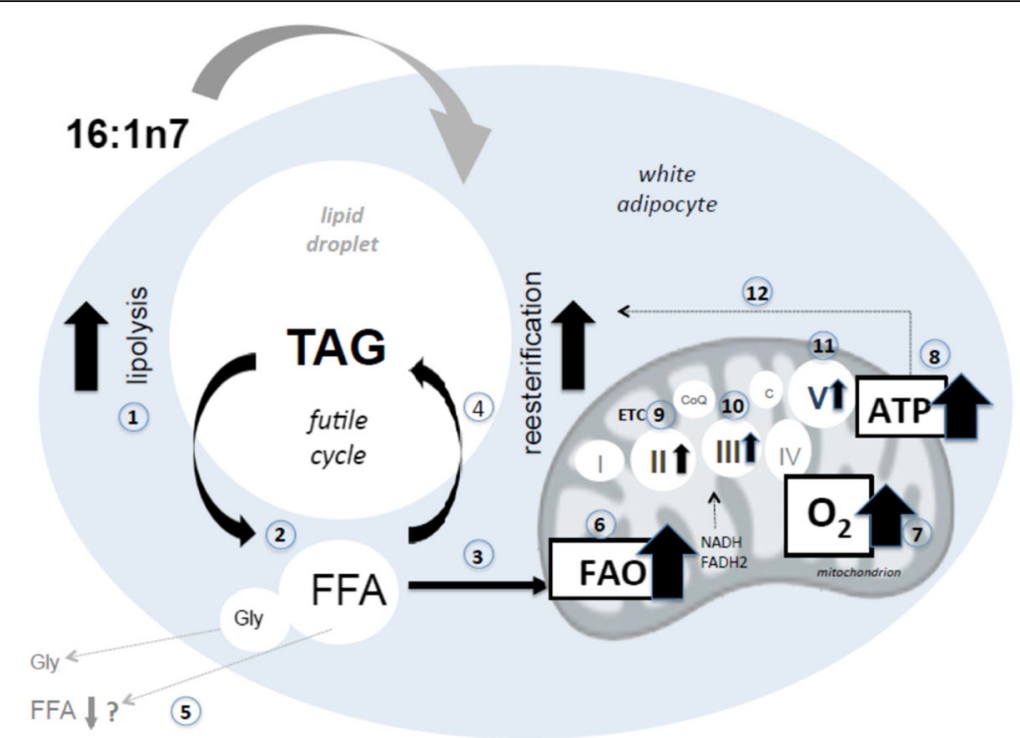

Fig. 8 Treatment with 16:1n7 for 9 days stimulated both lipolysis (1) and FFA re-esterification (4) in 3 T3-L1 adipocytes. Raised lipolysis leads to FFA (2) and glycerol release. FFA follow different fates (3): re-esterification into TAG (4), plasma (5) and mitochondria oxidation (6). 16:1n7 raised mitochondrial parameters such as FAO (6), oxygen consumption (7) and ATP generation (8). In addition, ETC protein expression is also elevated by 16:n7: complex II (9), complex III (10) and ATP synthase (11). ATP augmentation contributes to reesterification (12). Altogether, 16:1n7 enhances WAT futile cycle (lipolysis-re-esterification cycle) as well as mitochondria bioenergetics

consumption, beta-oxidation, lipolysis and lipogenesis, which corroborates an increased intrinsic mitochondrial function as a physiologic adaptation. It is currently accepted that mitochondria are dynamic organelles, which adjust according to the cell's energy demand.

Mitochondrial function (particularly OXPHOS uncoupling and FA oxidation) is considered a crucial factor to improve systemic insulin sensitivity [56-59]. Mitochondrial oxidative capacity in WAT correlates negatively with adiposity [50]. For example, a WAT knockout mouse for Liver Receptor X alpha (ATaKO mouse) was generated and presented more weight gain and fat mass on a high-fat diet compared with wildtype controls as a result of the decrease in WAT lipolytic and oxidative capacities [60]. Accordingly, LXR activation in vivo and in vitro led to decreased WAT adipocyte size and increased glycerol release from primary adipocytes, respectively, with a concomitant increase in oxygen consumption [40]. Thereby, novel compounds with potential to stimulate lipolysis, TAG/ FA cycle, FA oxidation in WAT are desired in therapies focusing obesity and related diseases.

\section{Conclusions}

In conclusion, our data show that palmitoleic acid plays an important role on WAT metabolic and mitochondrial function, suggesting an increase in energy expenditure of adipocytes by TAG/FA cycle acceleration, FA oxidation and oxygen consumption and, thus, raised cell energy metabolism. We presented herein evidence indicating that palmitoleic acid, by concerted action on lipolysis, mitochondrial FA oxidation, ATP content and oxygen consumption, contributes to enhance white adipocyte energy expenditure and could be considered as a possible candidate for clinical research related to adipose tissue (Fig. 8). We believe that palmitoleic acid treatment alone or its combination with caloric restriction and/or exercise is a promise for future obesity treatment/prevention. Nevertheless, the mechanisms involved in palmitoleicinduced TAG/FA cycle stimulation via mitochondria function have to be fully elucidated.

\section{Abbreviations \\ AMPK: AMP-activated protein kinase; aP2/FABP4: Fatty acid binding protein 4; ATGL/PNPLA2: Adipocyte triacylglycerol lipase; ATP: Adenosine 5'- triphosphate; BMR: Basal metabolic rate; CCCP: Carbonyl cyanide m- chlorophenyl hydrazine; COXIV: Cytochrome c oxidase subunit IV; DMEM: Dulbeccos modified eagle medium; ETC: Electron tranport chain; FA: Fatty acid; $\mathrm{FADH}_{2}$ : Flavin adenine dinucleotide; FAO: Fatty acid oxidation; FAS/FASN: Fatty acid synthase; FBS: Fetal bovine serum; FFA: Free fatty acid; G3-P: Glycerol 3-phosphate; G6PDH/H6PDH: Glucose 6 phosphate dehydrogenase; GLUT: Glucose transporter; HRR: High resolution respirometry; HSL/LIPE: Hormone sensitive lipase; KRH: Krebs ringer hepes bicarbonate buffer; LXRA: Liver X receptor alpha; NADH/NAD +: Nicotinamide adenine dinucleotide; OXPHOS: Oxidative phosphorylation; PBS: Phosphate buffered saline; PEPCK: Phosphoenolpyruvate carboxykinase; PKB or Akt: Protein kinase B; PPARa: Peroxisome proliferator-activated receptor alpha; TAG: Triacylglycerol; TAG/FA cycle: Triacylglycerol/fatty acid cycle; T2DM: Type 2 diabetes mellitus; UCP: Uncoupling protein; WAT: White adipose tissue}

Acknowledgments

The authors acknowledge to Gilson Murata for technical assistance. 


\section{Funding}

This work was supported by grants from FAPESP (2011/51627-8 and 2011/51701-3).

\section{Availability of data and materials}

All data generated or analyzed during this study are included in this published article.

\section{Authors' contributions}

MMC, ABL, ARC, RCCS and WMTK performed the experiments, analyzed the results and revised the manuscript. RC and PBMA designed the study, analyzed the results and revised the manuscript. MICAV designed the study, analyzed the results, wrote the manuscript and supervised the study. All authors read and approved the final manuscript.

\section{Ethics approval and consent to participate}

Not applicable.

\section{Consent for publication}

Not applicable.

\section{Competing interests}

The authors declare that they have no competing interests.

\section{Publisher's Note}

Springer Nature remains neutral with regard to jurisdictional claims in published maps and institutional affiliations.

\section{Author details \\ ${ }^{1}$ Department of Biological Sciences, Institute of Environmental Sciences, Chemical and Pharmaceutical, Federal University of São Paulo, 210, Sao Nicolau St, Diadema 09913-030, Brazil. ²Department of Physiology and Biophysics, Institute of Biomedical Sciences, University of São Paulo, São Paulo, Brazil. ${ }^{3}$ Interdisciplinary Postgraduate Program in Health Sciences, Institute of Physical Activity Sciences and Sports, Cruzeiro do Sul University, São Paulo, Brazil. ${ }^{4}$ Department of Nursing, Health Sciences Center, Federal University of Espírito Santo, Vitória, Brazil.}

\section{Received: 11 January 2018 Accepted: 13 March 2018}

\section{Published online: 20 March 2018}

\section{References}

1. Jensen MD. Lipolysis: contribution from regional fat. Annu Rev Nutr. 1997; 17:127-39. https://doi.org/10.1146/annurev.nutr.17.1.127. PubMed PMID: 9240922.

2. Ruge T, Hodson L, Cheeseman J, Dennis AL, Fielding BA, Humphreys SM, et al. Fasted to fed trafficking of fatty acids in human adipose tissue reveals a novel regulatory step for enhanced fat storage. J Clin Endocrinol Metab. 2009;94(5):1781-8. https://doi.org/10.1210/jc.2008-2090. PubMed PMID: 19223522

3. Sethi JK, Vidal-Puig AJ. Thematic review series: adipocyte biology. Adipose tissue function and plasticity orchestrate nutritional adaptation. J Lipid Res. 2007:48(6):1253-62. https://doi.org/10.1194/jlr.R700005-JLR200. PubMed PMID: 17374880; PubMed Central PMCID: PMC4303760

4. Lanza IR, Nair KS. Functional assessment of isolated mitochondria in vitro. Methods Enzymol. 2009;457:349-72. https://doi.org/10.1016/S00766879(09)05020-4. PubMed PMID: 19426878; PubMed Central PMCID: PMC2782617.

5. Carriere A, Fernandez Y, Rigoulet M, Penicaud L, Casteilla L. Inhibition of preadipocyte proliferation by mitochondrial reactive oxygen species. FEBS Lett. 2003;550(1-3):163-7. PubMed PMID: 12935904.

6. De Pauw A, Tejerina S, Raes M, Keijer J, Arnould T. Mitochondrial (dys) function in adipocyte (de)differentiation and systemic metabolic alterations. Am J Pathol. 2009;175(3):927-39. https://doi.org/10.2353/ajpath.2009.081155. PubMed PMID: 19700756; PubMed Central PMCID: PMC2731113.

7. Kita T, Nishida H, Shibata H, Niimi S, Higuti T, Arakaki N. Possible role of mitochondrial remodelling on cellular triacylglycerol accumulation. J Biochem. 2009;146(6):787-96. https://doi.org/10.1093/jb/mvp124. PubMed PMID: 19671539

8. Kaaman M, Sparks LM, van Harmelen V, Smith SR, Sjolin E, Dahlman I, et al. Strong association between mitochondrial DNA copy number and lipogenesis in human white adipose tissue. Diabetologia. 2007;50(12):252633. https://doi.org/10.1007/s00125-007-0818-6. PubMed PMID: 17879081.

9. Sutherland LN, Bomhof MR, Capozzi LC, Basaraba SA, Wright DC. Exercise and adrenaline increase PGC-1\{alpha\} mRNA expression in rat adipose tissue. J Physiol. 2009;587(Pt 7):1607-17. https://doi.org/10.1113/jphysiol. 2008.165464. PubMed PMID: 19221126; PubMed Central PMCID: PMC2678229.

10. Duchen MR. Mitochondria in health and disease: perspectives on a new mitochondrial biology. Mol Asp Med. 2004;25(4):365-451. https://doi.org/10. 1016/j.mam.2004.03.001. PubMed PMID: 15302203.

11. Geisler JG. Targeting energy expenditure via fuel switching and beyond. Diabetologia. 2011;54(2):237-44. https://doi.org/10.1007/s00125-010-1932-4. PubMed PMID: 20953861.

12. Cao H, Gerhold K, Mayers JR, Wiest MM, Watkins SM, Hotamisligil GS. Identification of a lipokine, a lipid hormone linking adipose tissue to systemic metabolism. Cell. 2008;134(6):933-44. https://doi.org/10.1016/j.cell.2008.07.048. PubMed PMID: 18805087: PubMed Central PMCID: PMC2728618

13. Dimopoulos N, Watson M, Sakamoto K, Hundal HS. Differential effects of palmitate and palmitoleate on insulin action and glucose utilization in rat L6 skeletal muscle cells. Biochem J. 2006;399(3):473-81. https://doi.org/10. 1042/BJ20060244. PubMed PMID: 16822230; PubMed Central PMCID: PMC1615906.

14. Obanda DN, Cefalu WT. Modulation of cellular insulin signaling and PTP1B effects by lipid metabolites in skeletal muscle cells. J Nutr Biochem. 2013; 24(8):1529-37. https://doi.org/10.1016/j.jnutbio.2012.12.014. PubMed PMID: 23481236: PubMed Central PMCID: PMC4509740.

15. Yang $\mathrm{ZH}$, Miyahara $\mathrm{H}$, Hatanaka A. Chronic administration of palmitoleic acid reduces insulin resistance and hepatic lipid accumulation in KK-Ay mice with genetic type 2 diabetes. Lipids Health Dis. 2011;10:120. https:// doi.org/10.1186/1476-511X-10-120. PubMed PMID: 21774832; PubMed Central PMCID: PMC3155149.

16. Diakogiannaki E, Dhayal S, Childs CE, Calder PC, Welters HJ, Morgan NG. Mechanisms involved in the cytotoxic and cytoprotective actions of saturated versus monounsaturated long-chain fatty acids in pancreatic betacells. J Endocrinol. 2007;194(2):283-91. https://doi.org/10.1677/JOE-07-0082. PubMed PMID: 17641278; PubMed Central PMCID: PMC1994570.

17. Morgan NG, Dhayal S. Unsaturated fatty acids as cytoprotective agents in the pancreatic beta-cell. Prostaglandins Leukot Essent Fatty Acids. 2010;82(4-6): 231-6. https:/doi.org/10.1016/j.plefa.2010.02.018. PubMed PMID: 20206490

18. Bolsoni-Lopes A, Festuccia WT, Farias TS, Chimin P, Torres-Leal FL, Derogis PB, et al. Palmitoleic acid (n-7) increases white adipocyte lipolysis and lipase content in a PPARalpha-dependent manner. Am J Physiol Endocrinol Metab. 2013:305(9):E1093-102. https://doi.org/10.1152/ajpendo.00082.2013. PubMed PMID: 24022867.

19. Bolsoni-Lopes A, Festuccia WT, Chimin P, Farias TS, Torres-Leal FL, Cruz MM et al. Palmitoleic acid (n-7) increases white adipocytes GLUT4 content and glucose uptake in association with AMPK activation. Lipids Health Dis. 2014; 13:199. https://doi.org/10.1186/1476-511X-13-199. PubMed PMID: 25528561; PubMed Central PMCID: PMC4364637.

20. Park BH, Qiang L, Farmer SR. Phosphorylation of C/EBPbeta at a consensus extracellular signal-regulated kinase/glycogen synthase kinase 3 site is required for the induction of adiponectin gene expression during the differentiation of mouse fibroblasts into adipocytes. Mol Cell Biol. 2004; 24(19):8671-80. https://doi.org/10.1128/MCB.24.19.8671-8680.2004. PubMed PMID: 15367685; PubMed Central PMCID: PMC516726.

21. Cruz MM. Efeitos dos ácidos graxos palmítico e palmitoleico sobre parâmetros metabólicos de adipócitos 3T3-L1 [Mestrado]: Universidade Federal de São Paulo; 2015.

22. de Sa RD, Crisma AR, Cruz MM, Martins AR, Masi LN, do Amaral CL, et al. Fish oil prevents changes induced by a high-fat diet on metabolism and adipokine secretion in mice subcutaneous and visceral adipocytes. J Physiol. 2016:594(21):6301-17. https://doi.org/10.1113/JP272541. Epub 2016/11/02. PubMed PMID: 27558442; PubMed Central PMCID: PMCPMC5088242.

23. Amengual J, Petrov $\mathrm{P}$, Bonet ML, Ribot J, Palou A. Induction of carnitine palmitoyl transferase 1 and fatty acid oxidation by retinoic acid in HepG2 cells. Int J Biochem Cell Biol. 2012;44(11):2019-27. https://doi.org/10.1016/j. biocel.2012.07.026. PubMed PMID: 22871568.

24. Mercader J, Madsen L, Felipe F, Palou A, Kristiansen K, Bonet ML. All-trans retinoic acid increases oxidative metabolism in mature adipocytes. Cell Physiol Biochem. 2007:20(6):1061-72. https://doi.org/10.1159/0000110717. PubMed PMID: 17975308. 
25. Shen W, Liu K, Tian C, Yang L, Li X, Ren J, et al. R-alpha-lipoic acid and acetyl-L-carnitine complementarily promote mitochondrial biogenesis in murine 3T3-L1 adipocytes. Diabetologia. 2008;51(1):165-74. https://doi.org/ 10.1007/s00125-007-0852-4. PubMed PMID: 18026715.

26. de Andrade PB, Rubi B, Frigerio F, van den Ouweland JM, Maassen JA, Maechler P. Diabetes-associated mitochondrial DNA mutation A3243G impairs cellular metabolic pathways necessary for beta cell function. Diabetologia. 2006;49(8):1816-26. https://doi.org/10.1007/s00125-006-0301-9. PubMed PMID: 16736129.

27. Tourniaire F, Musinovic H, Gouranton E, Astier J, Marcotorchino J, Arreguin A, et al. All-trans retinoic acid induces oxidative phosphorylation and mitochondria biogenesis in adipocytes. J Lipid Res. 2015;56(6):1100-9. https://doi.org/10.1194/jlr.M053652. Epub 2015/04/29. PubMed PMID: 25914170; PubMed Central PMCID: PMCPMC4442868.

28. Alp PR, Newsholme EA, Zammit VA. Activities of citrate synthase and NAD +-linked and NADP+-linked isocitrate dehydrogenase in muscle from vertebrates and invertebrates. Biochem J. 1976;154(3):689-700.

29. Hodson L, Karpe F. Is there something special about palmitoleate? Curr Opin Clin Nutr Metab Care. 2013;16(2):225-31. https://doi.org/10.1097/MCO. Ob013e32835d2edf. PubMed PMID: 23324899.

30. Talbot NA, Wheeler-Jones CP, Cleasby ME. Palmitoleic acid prevents palmitic acid-induced macrophage activation and consequent p38 MAPK-mediated skeletal muscle insulin resistance. Mol Cell Endocrinol. 2014:393(1-2):129-42. https://doi.org/10.1016/j.mce.2014.06.010. PubMed PMID: 24973767; PubMed Central PMCID: PMC4148479.

31. Forest C, Tordjman J, Glorian M, Duplus E, Chauvet G, Quette J, et al. Fatty acid recycling in adipocytes: a role for glyceroneogenesis and phosphoenolpyruvate carboxykinase. Biochem Soc Trans. 2003;31 (6):1125-9. Portland Press Ltd. https://doi.org/10.1042/bst0311125.

32. Reidy SP, Weber JM. Accelerated substrate cycling: a new energy-wasting role for leptin in vivo. Am J Physiol Endocrinol Metab. 2002;282(2):E312-7. https://doi.org/10.1152/ajpendo.00037.2001. PubMed PMID: 11788362

33. Wolfe RR, Klein S, Carraro F, Weber JM. Role of triglyceride-fatty acid cycle in controlling fat metabolism in humans during and after exercise. Am J Phys. 1990;258(2 Pt 1):E382-9. PubMed PMID: 2106269.

34. Klaman LD, Boss O, Peroni OD, Kim JK, Martino JL, Zabolotny JM, et al. Increased energy expenditure, decreased adiposity, and tissue-specific insulin sensitivity in protein-tyrosine phosphatase 1B-deficient mice. Mol Cell Biol. 2000; 20(15):5479-89. PubMed PMID: 10891488; PubMed Central PMCID: PMC85999.

35. Vallerand AL, Zamecnik J, Jones PJ, Jacobs I. Cold stress increases lipolysis, FFA Ra and TG/FFA cycling in humans. Aviat Space Environ Med. 1999;70(1): 42-50. PubMed PMID: 9895020.

36. Maassen JA, Romijn JA, Heine RJ. Fatty acid-induced mitochondrial uncoupling in adipocytes as a key protective factor against insulin resistance and beta cell dysfunction: a new concept in the pathogenesis of obesity-associated type 2 diabetes mellitus. Diabetologia. 2007;50(10):203641. https://doi.org/10.1007/s00125-007-0776-z. PubMed PMID: 17712547; PubMed Central PMCID: PMC2039833.

37. Baht HS, Saggerson ED. Comparison of triacylglycerol synthesis in rat brown and white adipocytes. Effects of hypothyroidism and streptozotocindiabetes on enzyme activities and metabolic fluxes. Biochem J. 1988;250(2): 325-33. PubMed PMID: 3355527; PubMed Central PMCID: PMC1148859.

38. Frayn KN, Langin D, Karpe F. Fatty acid-induced mitochondrial uncoupling in adipocytes is not a promising target for treatment of insulin resistance unless adipocyte oxidative capacity is increased. Diabetologia. 2008;51(3): 394-7. https://doi.org/10.1007/s00125-007-0901-z. PubMed PMID: 18097647.

39. Harper RD, Saggerson ED. Factors affecting fatty acid oxidation in fat cells isolated from rat white adipose tissue. J Lipid Res. 1976;17(5):516-26. PubMed PMID: 965842.

40. Dib L, Bugge A, Collins S. LXRalpha fuels fatty acid-stimulated oxygen consumption in white adipocytes. J Lipid Res. 2014;55(2):247-57. https://doi. org/10.1194/jlr.M043422. PubMed PMID: 24259533; PubMed Central PMCID: PMC3886663.

41. Wang T, Zang Y, Ling W, Corkey BE, Guo W. Metabolic partitioning of endogenous fatty acid in adipocytes. Obes Res. 2003;11(7):880-7. https:// doi.org/10.1038/oby.2003.121. PubMed PMID: 12855758.

42. den Hartigh LJ, Han CY, Wang S, Omer M, Chait A. 10E,12Z-conjugated linoleic acid impairs adipocyte triglyceride storage by enhancing fatty acid oxidation, lipolysis, and mitochondrial reactive oxygen species. J Lipid Res. 2013;54(11):2964-78. https://doi.org/10.1194/jlr.M035188. Epub 2013/08/21. PubMed PMID: 23956445; PubMed Central PMCID: PMCPMC3793601.
43. Vankoningsloo S, Piens M, Lecocq C, Gilson A, De Pauw A, Renard P, et al. Mitochondrial dysfunction induces triglyceride accumulation in 3T3-L1 cells: role of fatty acid beta-oxidation and glucose. J Lipid Res. 2005;46(6):113349. https://doi.org/10.1194/jlr.M400464-JLR200. PubMed PMID: 15741651

44. Heinonen S, Buzkova J, Muniandy M, Kaksonen R, Ollikainen M, Ismail K, et al. Impaired mitochondrial biogenesis in adipose tissue in acquired obesity. Diabetes. 2015;64(9):3135-45. https://doi.org/10.2337/db14-1937. PubMed PMID: 25972572.

45. Garlid KD, Jaburek M, Jezek P. Mechanism of uncoupling protein action. Biochem Soc Trans. 2001;29(Pt 6):803-6. PubMed PMID: 11709078.

46. Crescenzo R, Bianco F, Mazzoli A, Giacco A, Liverini G, lossa S. Skeletal muscle mitochondrial energetic efficiency and aging. Int J Mol Sci. 2015; 16(5):10674-85. https://doi.org/10.3390/ijms160510674. PubMed PMID: 25970752; PubMed Central PMCID: PMC4463669.

47. Gao CL, Zhu C, Zhao YP, Chen XH, Ji CB, Zhang CM, et al. Mitochondrial dysfunction is induced by high levels of glucose and free fatty acids in 3T3L1 adipocytes. Mol Cell Endocrinol. 2010;320(1-2):25-33. https://doi.org/10. 1016/j.mce.2010.01.039. Epub 2010/02/11. PubMed PMID: 20144685.

48. Lobo S, Wiczer BM, Bernlohr DA. Functional analysis of long-chain acyl-CoA synthetase 1 in 3T3-L1 adipocytes. J Biol Chem. 2009;284(27):18347-56. https://doi.org/10.1074/jbc.M109.017244. PubMed PMID: 19429676; PubMed Central PMCID: PMC2709349.

49. Baldwin RL. Metabolic functions affecting the contribution of adipose tissue to total energy expenditure, Fed. Proc. 1970;29:1277-83.

50. Flachs P, Rossmeisl M, Kuda O, Kopecky J. Stimulation of mitochondrial oxidative capacity in white fat independent of UCP1: a key to lean phenotype. Biochim Biophys Acta. 2013;1831(5):986-1003. https://doi.org/10. 1016/j.bbalip.2013.02.003. PubMed PMID: 23454373.

51. Carracedo A, Cantley LC, Pandolfi PP. Cancer metabolism: fatty acid oxidation in the limelight. Nat Rev Cancer. 2013;13(4):227-32. https://doi. org/10.1038/nrc3483. PubMed PMID: 23446547; PubMed Central PMCID: PMC3766957.

52. Gauthier MS, Miyoshi H, Souza SC, Cacicedo JM, Saha AK, Greenberg AS, et al. AMP-activated protein kinase is activated as a consequence of lipolysis in the adipocyte: potential mechanism and physiological relevance. J Biol Chem. 2008;283(24):16514-24. https://doi.org/10.1074/jbc.M708177200. PubMed PMID: 18390901; PubMed Central PMCID: PMC2423258.

53. Liu Q, Gauthier MS, Sun L, Ruderman N, Lodish H. Activation of AMPactivated protein kinase signaling pathway by adiponectin and insulin in mouse adipocytes: requirement of acyl-COA synthetases FATP1 and Acsl1 and association with an elevation in AMP/ATP ratio. FASEB J. 2010;24(11): 4229-39. https://doi.org/10.1096/fj.10-159723. PubMed PMID: 20667975; PubMed Central PMCID: PMC2974418.

54. Rogge MM. The role of impaired mitochondrial lipid oxidation in obesity. Biol Res Nurs. 2009;10(4):356-73. https://doi.org/10.1177/1099800408329408. PubMed PMID: 19190032.

55. Ahmadian M, Duncan RE, Sul HS. The skinny on fat: lipolysis and fatty acid utilization in adipocytes. Trends Endocrinol Metab. 2009;20(9):424-8. https:// doi.org/10.1016/j.tem.2009.06.002. PubMed PMID: 19796963; PubMed Central PMCID: PMC2764815.

56. Harms M, Seale P. Brown and beige fat: development, function and therapeutic potential. Nat Med. 2013;19(10):1252-63. https://doi.org/10. 1038/nm.3361. PubMed PMID: 24100998.

57. Roman S, Agil A, Peran M, Alvaro-Galue E, Ruiz-Ojeda FJ, Fernandez-Vazquez $\mathrm{G}$, et al. Brown adipose tissue and novel therapeutic approaches to treat metabolic disorders. Transl Res. 2015;165(4):464-79. https://doi.org/10.1016/j. trsl.2014.11.002. PubMed PMID: 25433289.

58. Rousset S, Alves-Guerra MC, Mozo J, Miroux B, Cassard-Doulcier AM, Bouillaud F, et al. The biology of mitochondrial uncoupling proteins. Diabetes. 2004;53(Suppl 1):S130-5. PubMed PMID: 14749278.

59. Surwit RS, Wang S, Petro AE, Sanchis D, Raimbault S, Ricquier D, et al. Dietinduced changes in uncoupling proteins in obesity-prone and obesityresistant strains of mice. Proc Natl Acad Sci U S A. 1998;95(7):4061-5. PubMed PMID: 9520493; PubMed Central PMCID: PMC19963.

60. Bottcher $H$, Furst $P$. Decreased white fat cell thermogenesis in obese individuals. Int J Obes Relat Metab Disord. 1997;21(6):439-44. PubMed PMID: 9192226. 